\title{
Reparação do escalpo por retalhos livres microcirúrgicos
}

\section{Scalp reconstruction with microsurgical free flaps}

\author{
Luiz Fernando Nóbrega \\ FRANCIOSI $^{1}$ \\ Elisabete Seganfredo \\ $\mathrm{WEBER}^{2}$ \\ RonAldo Righesso ${ }^{3}$ \\ VALENTIM RodRigues \\ SAlgado Pizzoni ${ }^{2}$ \\ Marcel Pelini Molon ${ }^{4}$ \\ Maria Claudia Piccoli ${ }^{4}$
}

Trabalho realizado no Serviço de Microcirurgia Reconstrutiva do Hospital Cristo Redentor, Grupo Hospitalar Conceição, Porto Alegre, RS, Brasil.

Artigo submetido pelo SGP (Sistema de Gestão de Publicações) da RBCP.

Artigo recebido: $1 / 9 / 2010$ Artigo aceito: 3/12/2010

\begin{abstract}
RESUMO
Introdução: O escalpelamento, remoção do escalpo, antiga técnica de se obter troféus de guerra, pode ser observado nos dias atuais causado por outras diferentes maneiras. A queimadura elétrica, as mordeduras caninas, os tumores e as máquinas industriais são as principais responsáveis por este tipo de lesão. A pouca extensibilidade do couro cabeludo proporciona uma grande dificuldade no tratamento destas lesões, principalmente nas perdas cutâneas extensas. O reimplante do escalpo pode ser tentado, mas, na maioria das vezes, essa oportunidade é perdida pela falta de condições técnicas ou porque a gravidade da lesão não o permite. A transposição de retalhos livres microcirúrgicos associada a outros procedimentos tem sido a maneira mais eficiente de tratar este tipo de lesão. Todos os pacientes incluídos neste trabalho tiveram boa evolução, com a resolução do problema inicial.
\end{abstract}

Descritores: Retalhos cirúrgicos. Dispositivos para expansão de tecidos. Couro cabeludo/ cirurgia.

\begin{abstract}
Background: The scalping, removal of the scalp, old technique of getting trophies of war, can be observed today, caused by other ways. The electrical burn, dog bites and industrial machinery are the main responsible for this kind of injury. The limited extensibility of the scalp, brings a major difficulty in treating these lesions, especially if the skin loss is extensive. The reimplantation of the scalp should be tried, but often this opportunity is lost for lack of technical and because the severity of the injury does not allow. The transposition of microsurgical free flaps combined with other procedures has been the most effective way to treat this type of injury. All patients included in this work showed good recovery, with resolution of the initial problem.
\end{abstract}

Keywords: Surgical flaps. Tissue expansion devices. Scalp/surgery.

\section{INTRODUÇÃO}

O escalpelamento, ato de remover uma parte do escalpo, é causado por queimaduras elétricas, mordeduras caninas, acidentes com maquinário industrial, ressecção de extensos tumores, entre outras causas ${ }^{1-3}$. Trata-se de uma situação grave que, na maioria das vezes, deixa sequelas importantes ao seu portador.

As lesões mais graves são as causadas pela queimadura elétrica ${ }^{4,5}$. A corrente elétrica é transformada em energia térmica, o que acaba causando a injúria tecidual. O grau de dano é determinado pela intensidade e duração do calor gerado. A tábua óssea frequentemente fica prejudicada nas queimaduras elétricas, podendo levar à necrose de uma ou de ambas tábuas da calvária ${ }^{6-9}$. A confecção de retalhos livres é um procedimento cirúrgico realizado em um único tempo, que provê cobertura às áreas queimadas com um tecido viável e vascularizado ${ }^{10-12}$.

O escalpelamento causado pela mordedura canina ou por algum tipo de maquinário industrial costuma preservar a tábua óssea externa, porém, na maioria dos casos, compromete o periósteo ${ }^{13}$. Este tipo de lesão necessita uma cobertura

1. Cirurgião Plástico; Membro Titular da Sociedade Brasileira de Cirurgia Plástica; Membro Titular da Sociedade Brasileira de Microcirurgia Reconstrutiva; Chefe do Serviço de Microcirurgia do Hospital Cristo Redentor, Grupo Hospitalar Conceição, Porto Alegre, RS, Brasil.

2. Cirurgião Plástico; Membro Especialista da Sociedade Brasileira de Cirurgia Plástica.

3. Cirurgião Plástico; Membro Titular da Sociedade Brasileira de Cirurgia Plástica.

4. Médico Residente do Serviço de Cirurgia Plástica do Hospital Ernesto Dornelles, Porto Alegre, RS, Brasil. 
cutânea, que não poderá ser o enxerto e que seja eficiente para a prevenção de complicações, como úlceras de Marjolin.

Os procedimentos cirúrgicos descritos para a correção de defeitos no escalpo são a perfuração da tábua externa, enxertos de pele, retalhos locais de couro cabeludo, retalhos pediculados distantes e retalhos livres ${ }^{2,8}$. Lutz et al. ${ }^{4}$ sugeriram que a seleção do melhor método para reconstrução deve ser considerada com base na etiologia, localização e período de tratamento.

Os retalhos livres são a melhor opção nos casos em que não existe tecido local adequado para confecção de retalho e também para defeitos extensos que envolvem o couro cabeludo, incluindo a fronte ${ }^{14,15}$. Dentre as opções, o retalho livre de latissimus dorsi tem muitas vantagens, como uma quantidade grande de tecido, um pedículo longo e de bom calibre, uma morbidade da área doadora pequena e uma grande versatilidade, podendo ser utilizado em uma série de situações ${ }^{16,17}$. Além disso, a taxa de insucesso é baixa e ele pode ser usado em combinação com o serrátil anterior para cobertura de áreas ainda mais extensas ${ }^{18}$.

Para obtenção de um melhor resultado cosmético, podem ser utilizados expansores teciduais ${ }^{19,20}$. Eles fornecem pele local para uma melhor cobertura da área de alopecia. A vantagem é a de repor um tecido exatamente com o mesmo tipo de tecido do couro cabeludo ${ }^{21}$. Este tipo de expansão pode ser realizado posteriormente ao fechamento do escalpo com retalhos ${ }^{22}$.

Este trabalho tem como objetivo discutir as várias técnicas para reconstrução do couro cabeludo, com ênfase aos retalhos livres que utilizam o músculo latissimus dorsi. Serão discutidas as vantagens e desvantagens deste procedimento, além de relatar a eficácia do uso de expansores cutâneos como alternativa para um melhor resultado estético.

\section{MÉTODO}

Foram selecionados para este trabalho 11 pacientes vítimas de escalpelamento por trauma, ressecção de grande massa tumoral ou queimadura elétrica, no período de 1998 a 2010.

Os critérios de inclusão foram pacientes que possuíam lesões extensas ou perda do periósteo com necessidade de reparo com retalho livre microcirúrgico. Pacientes com escalpelamento tratados com uso de enxertos ou retalhos locais foram excluídos.

Em todos os pacientes, foi realizada transferência do retalho muscular livre do latissimus dorsi, sobre o qual foi colocado um enxerto de pele parcial. A grande extensão da área a ser reparada determinou, em dois casos, a confecção de um retalho livre muscular de latissimus dorsi com uma porção cutânea e um retalho do músculo serrátil anterior com pedículo vascular único, ampliando a possibilidade de cobertura local. A pele trazida junto ao retalho foi usada para reconstruir de forma mais adequada a região frontal.

Em três casos, foram utilizados expansores tissulares para se obter um resultado final mais favorável, resolvendo de forma eficaz a alopecia.

\section{Técnica Cirúrgica}

A cirurgia inicia com o preparo da área receptora por meio do desbridamento de todo o tecido necrótico. Após, individualiza-se o pedículo receptor, geralmente os vasos temporais superficiais, sendo sua integridade fundamental para o sucesso do procedimento, como relatado por Hansen et al. ${ }^{17}$. Algumas vezes, em casos de queimadura elétrica grave, pode haver comprometimento destes vasos, sendo necessária a busca de outros pedículos receptores, como ramos da artéria carótida externa e da veia jugular externa.

A dissecção do retalho do músculo latissimus dorsi é feita de maneira convencional. Se necessário, pode-se agregar o músculo serrátil anterior e também uma porção cutânea sobre o músculo latissimus dorsi. Com o retalho totalmente dissecado e o pedículo de vasos tóraco-dorsais individualizado, realiza-se a ligadura deste pedículo e a transferência do retalho. Mesmo com o grande comprimento oferecido pela artéria tóraco-dorsal, não se descarta a possibilidade da utilização de enxertos venosos para que este pedículo encontre os vasos receptores. As anastomoses vasculares são realizadas com fio de nylon monofilamentar 8.0 ou 9.0 e o retalho tem os bordos fixados com fio de nylon monofilamentar 4.0 e sobre o mesmo é realizado um enxerto de pele parcial.

A zona doadora é fechada por sutura convencional e um dreno de sucção é colocado no local e retirado após um período que ocorra mínimo volume de drenagem.

\section{Expansores Teciduais}

A expansão de tecidos é um método confiável para se obter tecido cutâneo adicional. Os efeitos da expansão da pele, incluindo o aumento da área de superfície e da vascularização, possibilitam a cobertura de diversas feridas complexas. No couro cabeludo, a utilização de expansores teciduais favoreceu o tratamento de lesões que até então apresentavam resultados pouco satisfatórios. Foram utilizados expansores em três casos dentre os apresentados, com expansão gradativa e posterior avanço dos tecidos expandidos na forma de retalhos, criando

\begin{tabular}{c|c|c}
\hline \multicolumn{2}{c}{ Tabela 1 - Pacientes submetidos a tratamento cirúrgico. } \\
\hline Sexo & Etiologia & Cirurgia \\
\hline M & Queimadura elétrica & $\mathrm{Ld}$ \\
\hline M & Queimadura elétrica & $\mathrm{Ld}$ \\
\hline M & Queimadura elétrica & $\mathrm{Ld}$ \\
\hline M & Queimadura elétrica & $\mathrm{Ld}+\mathrm{S}$ \\
\hline M & Queimadura elétrica & $\mathrm{Ld}+\mathrm{E}$ \\
\hline F & Eixo de força de trator & $\mathrm{Ld}$ \\
\hline F & Eixo de força de trator & $\mathrm{Ld}+\mathrm{S}+\mathrm{E}$ \\
\hline F & Eixo de força de trator & $\mathrm{Ld}$ \\
\hline M & Mordedura canina & $\mathrm{Ld}$ \\
\hline F & Mordedura canina & $\mathrm{Ld}+\mathrm{E}$ \\
\hline M & Tumor & $\mathrm{Ld}$ \\
\hline
\end{tabular}

Ld - Latissimus dorsi; S - Serrátil anterior; E - Expansor tecidual. 
cobertura para as áreas de couro cabeludo onde havia presença de pele glabra remanescente. Nos três casos relatados, os resultados obtidos foram satisfatórios, com adequado reposicionamento dos tecidos e correção de sequelas.

\section{RESULTADOS}

Onze pacientes foram submetidos à transferência de retalho microcirúrgico do músculo latissimus dorsi para a reconstrução do escalpo com associação ou não de outro procedimento (Tabela 1 )

Todos os pacientes obtiveram a cobertura total do defeito inicial por meio do retalho microcirúrgico. Em dois pacientes, foi realizado o retalho do músculo serrátil anterior agregado ao latissimus dorsi.

Em um dos casos, a artéria temporal superficial estava totalmente inutilizada por lesão de corrente elétrica. Neste caso, utilizou-se enxerto de veia, tanto para a anastomose arterial como para a venosa. Os vasos receptores foram a veia jugular externa e a artéria tireoideia superior.

Não houve nenhuma necrose de retalho muscular livre. Em um caso, não ocorreu integração total dos enxertos de pele parcial sobre o retalho.

A incidência de seroma na área doadora do retalho muscular foi frequente.

As Figuras 1 a 6 ilustram alguns casos dessa casuística.
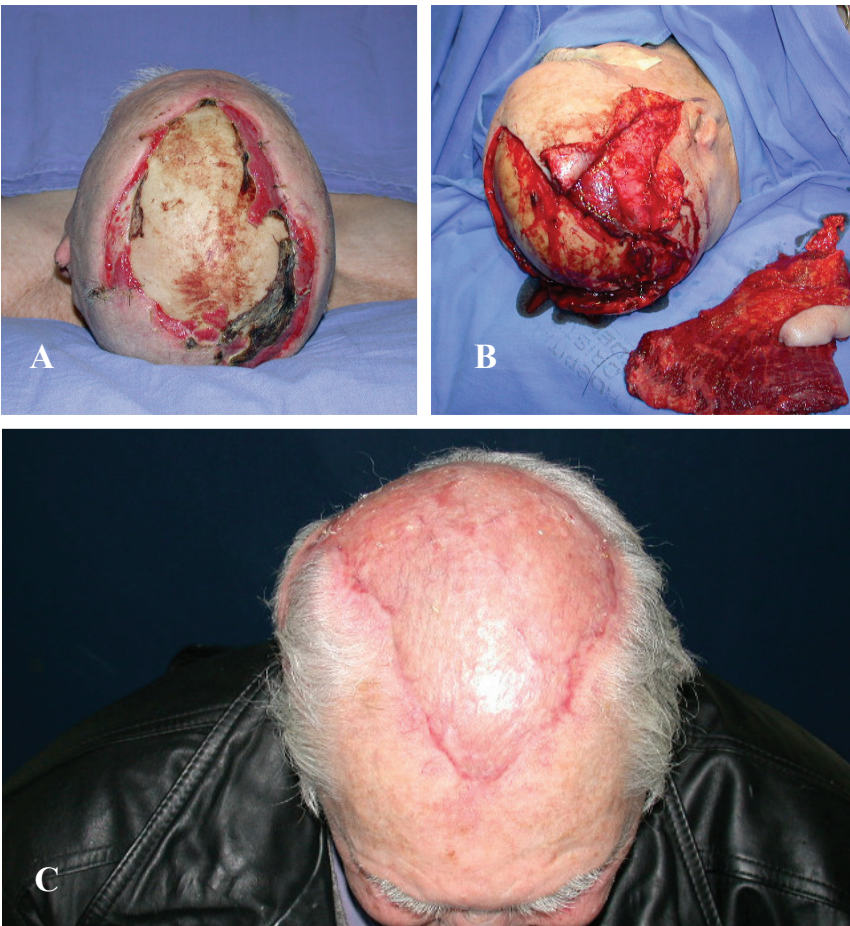

Figura 1-Caso 1. A: Pré-operatório - Escalpelamento por mordedura canina. Transferência de retalho muscular de latissimus dorsi e enxertia de pele. B:Transoperatório. C: Pós-operatório.

\section{DISCUSSÃO}

A perda de substância localizada no couro cabeludo acompanha-se de uma série de dificuldades para sua resolução. Mesmo perdas pequenas podem exigir confecção de retalhos locais, uma vez que a pouca extensibilidade do couro cabeludo não permite aproximação simples bordo a bordo ${ }^{11,21}$.

No passado, eram realizados pequenos orifícios na tábua externa do crânio após desbridamento do tecido necrótico, com posterior enxertia cutânea quando do estabelecimento do tecido de granulação. Este método levava a períodos de hospitalização prolongados, aumentando o risco de infecção, fornecendo pobres resultados estéticos, e ainda adicionando potencial de malignidade à uma ulceração do enxerto ${ }^{5,7}$.
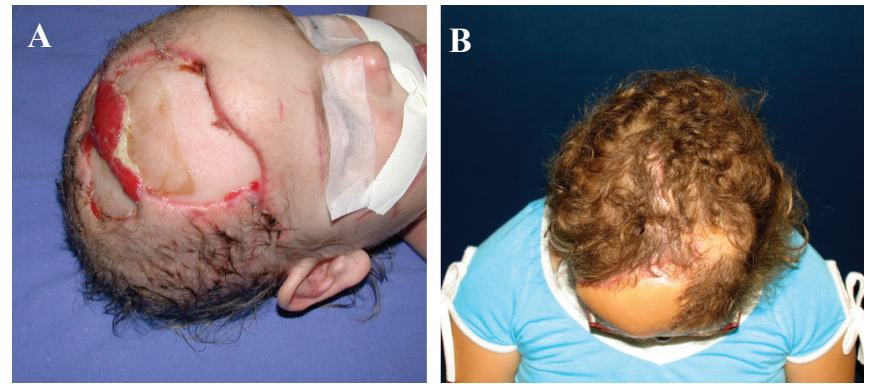

Figura 2-Caso 2. A: Pré-operatório - Escalpelamento por mordedura canina. Transferência de retalho livre miocutâneo de latissimus dorsi com a parte cutânea para reconstrução da fronte. B: Pós-operatório.
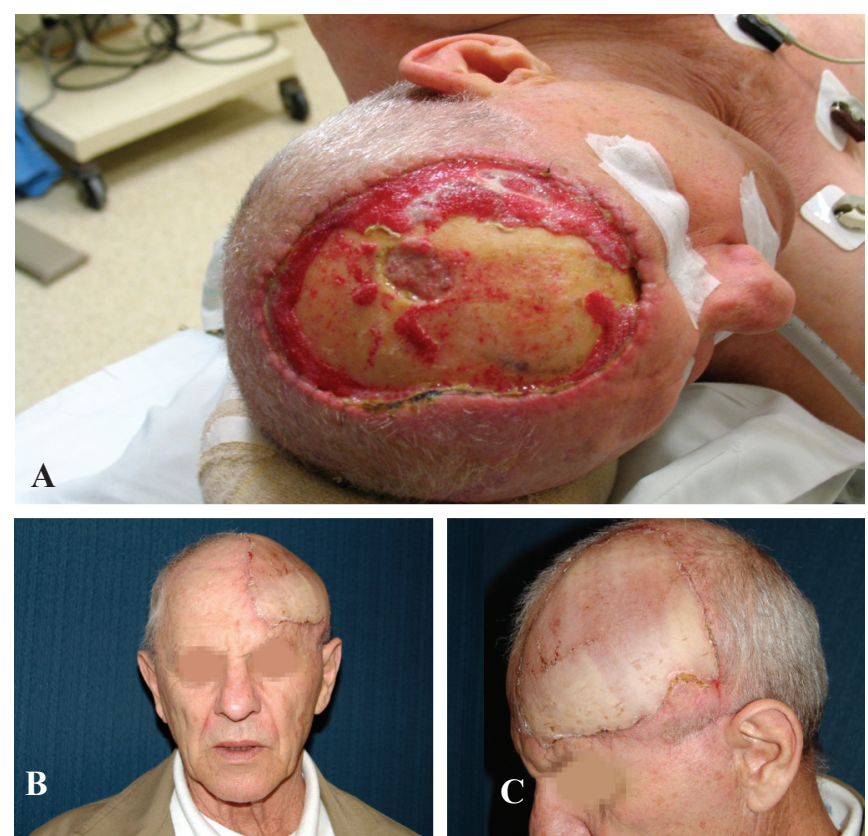

Figura 3-Caso 3. A: Pré-operatório - Escalpelamento por tumoração (carcinoma espinocelular). Remoção de tábua externa invadida pelo tumor + transferência de retalho livre de latissimus dorsi e enxertia de pele. $\boldsymbol{B}$ e $\boldsymbol{C}$ : Pós-operatório. 

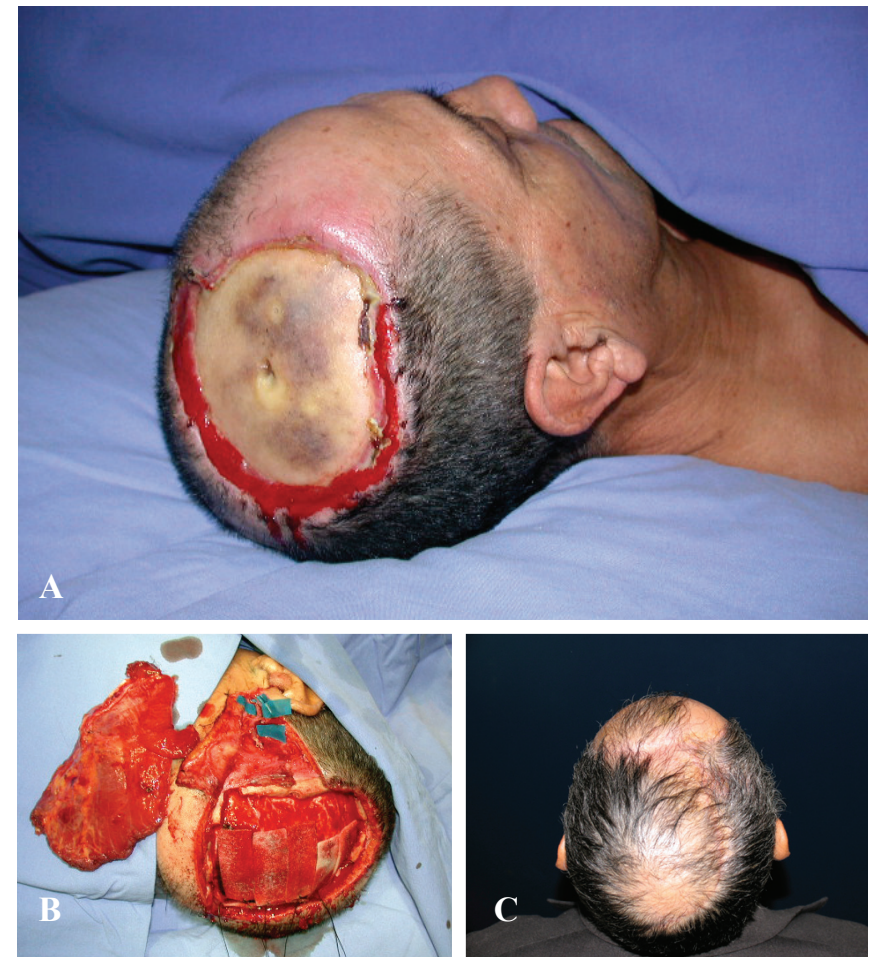

Figura 4-Caso 4. A: Pré-operatório - Escalpelamento por queimadura elétrica. Transferência de retalho livre de latissimus dorsi com enxertia de pele + expansão cutânea para cobertura de área glabra remanescente. $\boldsymbol{B}$ : Transoperatório. $\boldsymbol{C}$ : Pós-operatório.
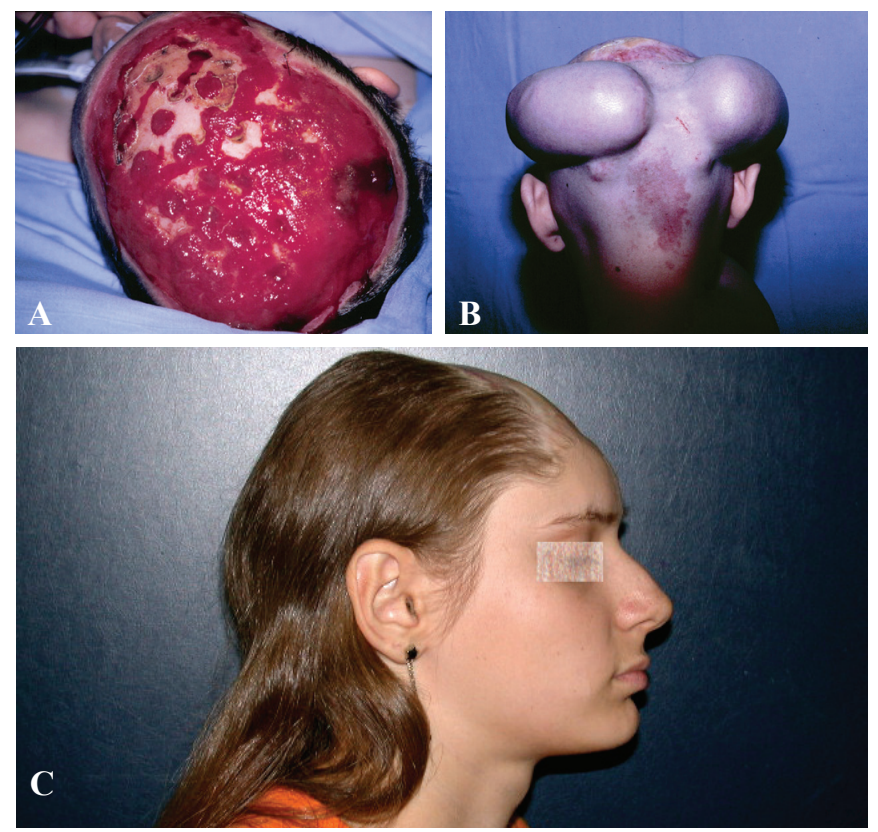

Figura 5-Caso 5. A: Pré-operatório - Escalpelamento por eixo de força de máquina. Transferência da latissimus dorsi e serrátil anterior com enxertia de pele e posterior expansão cutânea para cobertura de área glabra remanescente. B: Expansão tecidual póstransferência de retalho livre. $\boldsymbol{C}$ : Pós-operatório.
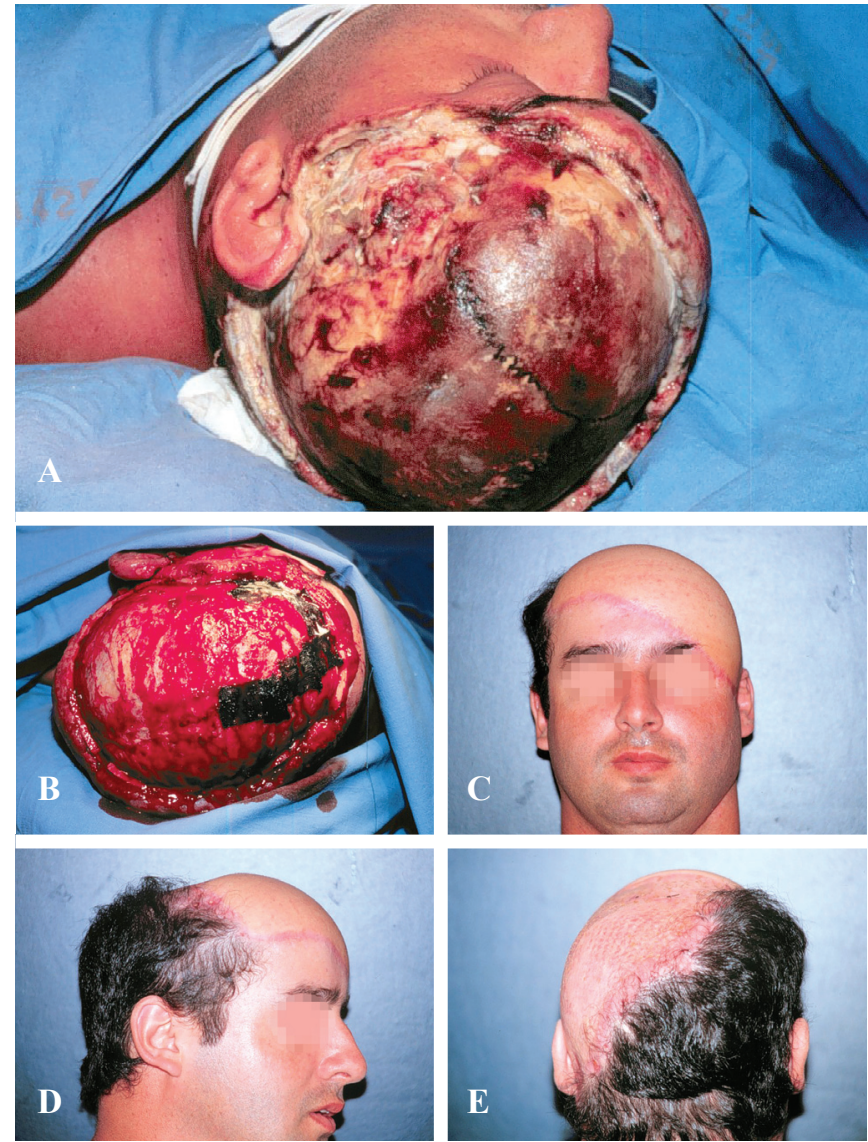

Figura 6-Caso 6. A: Pré-operatório - Escalpelamento por queimadura elétrica. Transferência de retalho livre miocutâneo de latissimus dorsi e serrátil anterior com a parte cutânea para reconstrução da fronte. $\boldsymbol{B}$ : Transoperatório com remoção de toda tábua externa e exposição da dura-máter. $\boldsymbol{C}, \boldsymbol{D}$ e E: Pósoperatório.

A presença de necrose da parte óssea apresenta-se como uma preocupação importante, pela possibilidade de exposição de tecido cerebral ${ }^{9,11-13}$. O retalho transposto deve ser eficaz, pois as complicações advindas de sua necrose são graves. A recomendação é o desbridamento de tecido e osso necróticos, seguido imediatamente por cobertura com retalhos locais, pediculados ou livres ${ }^{1,2-7}$. Essa cobertura com tecido viável e vascularizado estimula o crescimento ósseo e ajuda a prevenir a infecção associada à osteonecrose $\mathrm{e}^{6}$.

Retalhos locais de couro cabeludo apresentam desvantagens, como espessura insuficiente para cobrir defeitos profundos, necessidade de tecido perilesional intacto e, na sua maioria, por possuírem cabelos, não possibilitam o uso para cobertura da região frontal. As vantagens são dissecção rápida e fácil, além de vascularização segura. A indicação de retalhos locais é limitada aos defeitos do couro cabeludo de áreas pequenas a médias, não profundas e sem pêlos ${ }^{1,4,9}$. 
$\mathrm{Na}$ maioria dos casos de grandes defeitos do couro cabeludo, independente da etiologia, o retalho livre torna-se a principal e melhor opção. Existem numerosos sítios doadores para retalhos livres: para-escapular, latissimus dorsi isolado ou em combinação com o serrátil anterior, antebraço radial, omento, etc ${ }^{12}$. O retalho livre de latissimus dorsi apresenta algumas vantagens, como fornecer grande quantidade de tecido, ter um pedículo longo e de bom calibre, deixar pouca morbidade da área doadora e ainda possuir uma grande versatilidade, podendo ser utilizado em uma série de situações ${ }^{13}$. Além disso, pode ser usado em combinação com o serrátil anterior para cobertura de áreas ainda mais extensas ${ }^{12,16}$.

Beasley et al. ${ }^{14}$ propõem um sistema de estadiamento para a seleção do tipo de retalho a ser utilizado para reconstrução, baseado na etiologia e tamanho do defeito, tratamento prévio e planejamento de tratamento futuro. Para defeitos do couro cabeludo sugerem: os menores que $200 \mathrm{~cm}^{2}$ podem ser fechados primariamente ou com retalhos locais; para os menores que $200 \mathrm{~cm}^{2}$ associados a trauma grave, osteomielite ou oesteorradionecrose, radiação prévia, retalho local prévio e plano de radioterapia pós-operatória recomendam retalhos musculares livres de reto abdominal ou latissimus dorsi com enxerto cutâneo; nos de tamanho entre 200-600 cm², empregamse retalhos musculares livres de latissimus dorsi com enxerto cutâneo; nos maiores de $600 \mathrm{~cm}^{2}$, deve-se utilizar a associação de dois retalhos musculares livres de latissimus dorsi com enxerto de pele. Para defeitos na fronte, recomendam o uso de retalho livre musculocutâneo escapular para defeitos maiores que $50 \mathrm{~cm}^{2}$ e também para defeitos menores que $50 \mathrm{~cm}^{2}$ quando associados a trauma grave, osteomielite, radiação prévia, falha de retalho local prévia e plano de radioterapia pós-operatória9.

Nos casos de ferimentos por queimaduras elétricas no couro cabeludo em grandes áreas, retalhos livres e retalhos locais em casos selecionados, são as melhores soluções para a reconstrução $0^{1,4,12,14}$. A série de Dalay et al. ${ }^{8}$ consta de 15 pacientes com defeitos de couro cabeludo complexos secundários a queimaduras elétricas (3 retalhos miocutâneos livres de latissimus dorsi, um retalho livre de serrátil anterior, 1 retalho miocutâneo de pedículo distante de trapézio e 10 retalhos locais). Foi verificada por cintilografia a regeneração óssea. Expansor tecidual foi usado em 6 casos para cobertura da área com cabelo em uma fase posterior.

Entre as complicações mais frequentes deste tipo de procedimento estão necrose total ou parcial do retalho, não integração do enxerto cutâneo e seromas na área doadora (músculo latissimus dorsi). Na série de Ioannides et al. ${ }^{13}$, em que foram arrolados 31 pacientes com defeitos de couro cabeludo tratados com retalhos livres, houve perda de apenas um $(3,2 \%)$ retalho livre de latissimus dorsi, devido à isquemia venosa, estando dentro dos limites aceitáveis de $6,6 \%$ para esta área do corpo relatados por Kroll et al. ${ }^{16}$. Outras séries, que utilizaram retalhos livres para cobrir defeitos do couro cabeludo por diversas etiologias, obtiveram resultados diversos, com falhas variando de $6,6 \%^{4}$ até $14,2 \%{ }^{15}$. Chang et al. ${ }^{2}$ obtiveram bons resultados em uma série de casos com 5 retalhos fasciocutâneos e 7 retalhos miocutâneos, demonstrando ótimas opções para reconstrução de defeitos complicados de escalpo.

Resultados estéticos muito bons podem ser alcançados com a expansão tecidual para cobrir regiões onde a pele com cabelos foi perdida ${ }^{19,20,22}$. A principal vantagem é repor um tecido com características bastante semelhantes ao original. Seu uso não está indicado em casos de infecção e não está recomendado em área com pele irradiada devido à alta possibilidade de necrose cutânea.

\section{CONCLUSÃO}

Pequenas áreas do couro cabeludo podem ser facilmente cobertas com retalhos locais. A transposição de retalhos livres musculares para a reconstrução de grandes lesões causadas pelo escalpelamento permite concluir que esse método é bastante eficaz, sendo uma excelente opção para o tratamento. Os resultados obtidos foram satisfatórios. Vários pacientes foram acompanhados por longo período e nenhum deles apresentou necrose na área reconstruída. A utilização de expansores cutâneos, em um segundo momento, tem demonstrado resultados estéticos satisfatórios para cobertura remanescente do couro cabeludo.

\section{REFERÊNCIAS}

1. Wax MK, Kim J, Ducic Y. Update on major reconstruction of the head and neck. Arch Facial Plast Surg. 2007;9(6):392-9.

2. Chang KP, Lai CH, Chang CH, Lin CL, Lai CS, Lin SD. Free flap options for reconstruction of complicated scalp and calvarial defects: report of a series of cases and literature review. Microsurgery. 2010;30(1):13-8.

3. van Driel AA, Mureau MA, Goldstein DP, Gilbert RW, Irish JC, Gullane PJ, et al. Aesthetic and oncologic outcome after microsurgical reconstruction of complex scalp and forehead defects after malignant tumor resection: an algorithm for treatment. Plast Reconstr Surg. 2010;126(2):460-70.

4. Lutz BS, Wei FC, Chen HC, Lin CH, Wei CY. Reconstruction of scalp defects with free flaps in 30 cases. Br J Plast Surg. 1998;51(3):186-90.

5. Newman MI, Hanasono MM, Disa JJ, Cordeiro PG, Mehrara BJ. Scalp reconstruction: a 15-year experience. Ann Plast Surg. 2004;52(5):501-6.

6. Spies M, McCauley RL, Mudge BP, Herndon DN. Management of acute calvarial burns in children. J Trauma. 2003;54(4):765-9.

7. Hartford CE. Preservation of devitalized calvarium following highvoltage electrical injury: case reports. J Trauma. 1989;29(3):391-4.

8. Dalay C, Kesiktas E, Yavuz M, Ozerdem G, Acarturk S. Coverage of scalp defects following contact electrical burns to the head: a clinical series. Burns. 2006;32(2):201-7.

9. Wright HR, Drake DB, Gear AJ, Wheeler JC, Edlich RF. Industrial high-voltage electrical burn of the skull, a preventable injury. J Emerg Med. 1997;15(3):345-9. 
10. Afifi A, Djohan RS, Hammert W, Papay FA, Barnett AE, Zins JE. Lessons learned reconstructing complex scalp defects using free flaps and a cranioplasty in one stage. J Craniofac Surg. 2010;21(4):1205-9.

11. Angelos PC, Downs BW. Options for the management of forehead and scalp defects. Facial Plast Surg Clin North Am. 2009;17(3):379-93.

12. Pennington DG, Stern HS, Lee KK. Free-flap reconstruction of large defects of the scalp and calvarium. Plast Reconstr Surg. 1989;83(4):655-61.

13. Ioannides C,FossionE, McGroutherAD. Reconstruction forlargedefects of the scalp and cranium. J Craniomaxillofac Surg. 1999;27(3):145-52.

14. Beasley NJ, Gilbert RW, Gullane PJ, Brown DH, Irish JC, Neligan PC. Scalp and forehead reconstruction using free revascularized tissue transfer. Arch Facial Plast Surg. 2004;6(1):16-20.

15. Furnas H, Lineaweaver WC, Alpert BS, Buncke HJ. Scalp reconstruction by microvascular free tissue transfer. Ann Plast Surg. 1990;24(5):431-44.

16. Kroll SS, Schusterman MA, Reece GR, Miller MJ, Evans GR, Robb GL, et al. Choice of flap and incidence of free flap success. Plast Reconstr Surg. 1996;98(3):459-63.
17. Hansen SL, Foster RD, Dosanjh AS, Mathes SJ, Hoffman WY, Leon P. Superficial temporal artery and vein as recipient vessels for facial and scalp microsurgical reconstruction. Plast Reconstr Surg. 2007;120(7):1879-84.

18. Lee B, Bickel K, Levin S. Microsurgical reconstruction of extensive scalp defects. J Reconstr Microsurg. 1999;15(4):255-64.

19. Colonna M, Cavallini M, De Angelis A, Preis FW, Signorini M. The effects of scalp expansion on the cranial bone: a clinical, histological, and instrumental study. Ann Plast Surg. 1996;36(3):255-62.

20. Kane WJ, McCaffrey TV, Wang TD, Koval TM. The effect of tissue expansion on previously irradiated skin. Arch Otolaryngol Head Neck Surg. 1992;118(4):419-26.

21. Demir Z, Velidedeoglu H, Celebioglu S. V-Y-S plasty for scalp defects. Plast Reconstr Surg. 2003;112(4):1054-8.

22. Hoffman JF. Management of scalp defects. Otolaryngol Clin North Am 2001;34(3):571-82.

Correspondência para:

Luiz Fernando Nóbrega Franciosi

Av. Getúlio Vargas, 901 conj. 1303 - Porto Alegre, RS, Brasil - CEP: 90150-003

E-mail: franciosi@cirurgia-plastica.org 